\title{
Tensile properties of bamboo in different sizes
}

\author{
Hong Chen ${ }^{1,2} \cdot$ Haitao Cheng ${ }^{2} \cdot$ Ge Wang ${ }^{2} \cdot$ Zixuan $\mathrm{Yu}^{2} \cdot$ Sheldon Qiang $\mathrm{Shi}^{3}$
}

Received: 11 May 2015/ Accepted: 24 July 2015/Published online: 23 October 2015

(C) The Japan Wood Research Society 2015

\begin{abstract}
The objective of this study was to investigate the effect of specimen size on the mechanical properties of bamboo. Single bamboo fibers and bamboo fiber bundles obtained from both chemical retting and mechanical retting were tested. The tensile strength of chemically retted single bamboo fiber was $47.6 \%$ higher than that of the mechanically retted fibers. The tensile strength of the chemically retted fiber bundles was over 2.1 times higher than that of the mechanically retted one, while the tensile modulus was almost 1.4 times higher. For the chemical retting, the fiber bundles were $65.7 \%$ less in tensile strength compared to the single fiber, $12.3 \%$ less for the tensile modulus, and $9.7 \%$ less for the elongation. For the mechanical retting, the tensile strength, tensile modulus and elongation of fiber bundles were $68.8,52.3$ and $60.9 \%$ lower than that of the single fibers, respectively. Compared with single bamboo fibers and bamboo fiber bundles, the tensile strength of bamboo strips was reduced by 67.7 and $3.3 \%$, respectively. The modulus of bamboo fiber bundles was $42.7 \%$ less compared to the single bamboo fibers, and $16.9 \%$ higher compared to the bamboo fiber bundles. The mechanical properties of bamboo strips were lower than that of samples made from outer portion of the bamboo, but higher than that of samples made from inner portion of the bamboo.
\end{abstract}

Ge Wang

wangge@icbr.ac.cn

1 College of Furniture and Industrial Design, Nanjing Forest University, Nanjing 210037, China

2 International Center for Bamboo and Rattan, No. 8, Futong Dong Dajie, Wangjing Area, Chaoyang District, Beijing 100102, China

3 Mechanical and Energy Engineering, University of North Texas, Denton, TX 76203-1277, USA
Keywords Single bamboo fibers - Bamboo bundles . Bamboo strips - Mechanical properties

\section{Introduction}

The mechanical performance of bamboo-based composite products is highly dependent on the properties of bamboo elements used to make the products. Bamboo-based products are usually fabricated from single bamboo fibers, fiber bundles, and bamboo strips. To design and engineer the bamboo-based products to improve the utilization and manufacture of bamboo materials, it is essential to understand the differences in the mechanical properties of these bamboo elements as affected by the element sizes.

Jayne tested the mechanical properties of earlywood and latewood fibers from ten gymnosperm species. It was found that the fibers were generally Hookean in nature, displaying a proportional stress-strain relationship [1]. The average tensile stress and modulus of Douglas fir fibers were obtained as $0.85-0.91 \mathrm{GPa}$ and $23.60-24.50 \mathrm{GPa}$, respectively [2]. In addition, Mott et al. investigated the variations in mechanical properties of individual southern pine fibers and compared the engineering properties of earlywood and latewood tracheids with respect to the tree height and juvenility [3]. Meanwhile, Groom et al. defined juvenile, transition and mature zone as classified by fiber stiffness, strength, microfibril angle, and cross-sectional area [4]. Subsequently, the tensile properties of mechanically and chemically isolated spruce fibers were compared by micro-tensile investigation [5]. Recently, Wang et al. and $\mathrm{Yu}$ et al. presented an improved technique for single plant fiber characterization with custom-designed microtensile tester, from which the testing is easy to conduct, and the results are more accurate $[6,7]$. 
Okubo et al. presented the development of composites for ecological purposes using bamboo fibers bundles isolated by steam explosion technique and their basic mechanical properties [8]. It was found that the bamboo fiber bundles had a sufficient specific strength, which was equivalent to that of conventional glass fibers. Zhai et al. investigated the mechanical properties and structures of windmill palm fiber bundles, and found that the fiber bundles from the inner layer of windmill palm showed higher tensile strength $(0.11 \mathrm{GPa})$ and Young's modulus $(1.25 \mathrm{GPa})$ than that from the other layers [9]. In both Okubo and Zhai's methods, the cross-sectional areas of bamboo fiber bundle used for the calculation were from the averaged values of the individual fiber, of which the result might not be accurate. Bamboo fiber bundles have been used for the composite reinforcement [8, 10-12]. However, little studies have been conducted on effect of size of the bamboo, such as single bamboo fiber, fiber bundle, and bamboo strips on their tensile properties.

Recently, studies have been conducted on the mechanical properties of bamboo strips. Wang explored that the fracture mechanism of bamboo/Chinese fir composites in bending and shear by examining the failure images from scanning electron microscopy (SEM) [13]. For the longitudinal 3-point bending and shear test, crack failure in the tangential direction was observed rather than the glue bond failures for the Chinese fir or bamboo under the air-dry condition. However, after water soaking of the specimens, the failure happens at the interface between the fiber and the adhesive. Li studied the tensile properties of bamboo using the digital speckle correlation method (DSCM), and discovered that the mechanical properties of bamboo were lower than that of bamboo fibers because of the slips between the fibers [14]. In two previous papers [6, 15], the tensile properties of four types of individual natural fibers (bamboo, kenaf, Chinese fir and ramie) isolated by different methods were measured by a custom-designed microtensile tester. It was found from the load-displacement curves during the tension testing that most single fibers presented linear until failure.

The objective of this paper was to evaluate the tensile properties of single bamboo fibers, bamboo fiber bundles and bamboo strips retted from both chemical and mechanical methods.

\section{Experimental}

\section{Samples preparation}

One-year-old Cizhu bamboo (Neosinocalamus affinis) was obtained from Chengdu, Sichuan province, China, with an initial moisture content of 8-12\%. Single bamboo fibers and bamboo bundles were obtained from the part between the white lines of bamboo trunk as shown in Fig. 1 which was usually used in the factory.

Single bamboo fibers were isolated both chemically and mechanically. For the chemical retting process, the bamboo samples were cut into strips $(20 \mathrm{~mm}$ in length longitudinally and $2 \times 2 \mathrm{~mm}$ in cross section), and immersed in the chemical solution (one part $30 \%$ hydrogen peroxide, four part distilled water and five part glacial acetic acid) at a temperature of $60{ }^{\circ} \mathrm{C}$ for $42 \mathrm{~h}$, as shown in Fig. 2c, d. For the mechanical retting process, the bamboo materials were first softened in boiling water for $40 \mathrm{~h}$. And then the bamboo was cut into $90-\mu \mathrm{m}$-thick tangential slices from which the single fibers were peeled off by fine tweezers (Fig. 2a, b).

Bamboo fiber bundles were also obtained from both chemical and mechanical retting processes (shown in Fig. 3). Bamboo strips with a dimension of $15 \times 4 \times 2 \mathrm{~cm}$ (length $\times$ width $\times$ thickness) were immersed in an alkaline solution ( $5 \mathrm{wt} \% \mathrm{NaOH}$ ) for softening, which was a method used in the factory, then isolated using a comb. Besides, previous study on jute fibers demonstrated that fibers treated with $5 \mathrm{wt} \% \mathrm{NaOH}$ solutions provide better results in terms of physical, mechanical, and thermal properties compared to those in untreated one [16]. The mechanically isolated bamboo fiber bundles were obtained

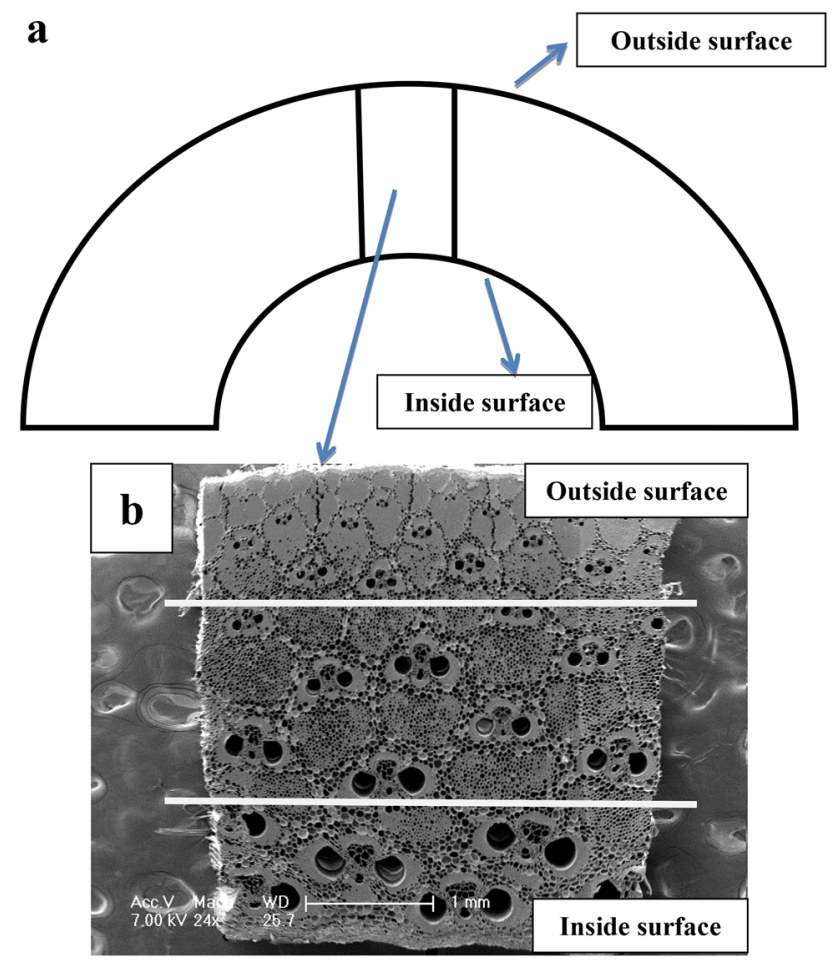

Fig. 1 Schematics of a the sample prepared from bamboo culm and b cross section of the sample; all fiber samples were prepared from the area between the two lines 

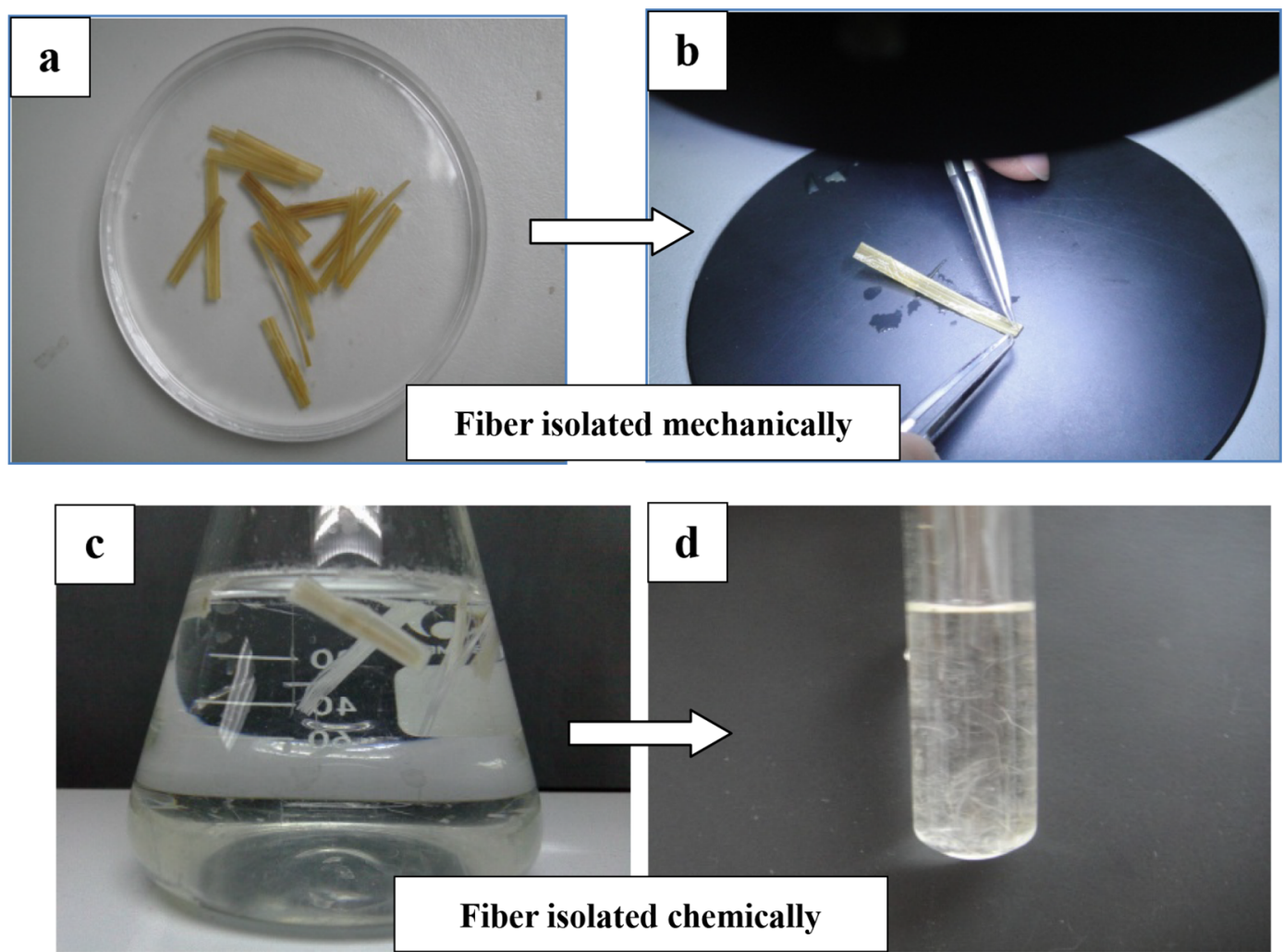

Fig. 2 Single bamboo fiber isolated mechanically and chemically, a $90-\mu \mathrm{m}$-thick tangential slices of bamboo, b single fibers peeled off by fine tweezers under microscope, $\mathbf{c}$ small bamboo strips immersed in the chemical solution, $\mathbf{d}$ single bamboo fibers

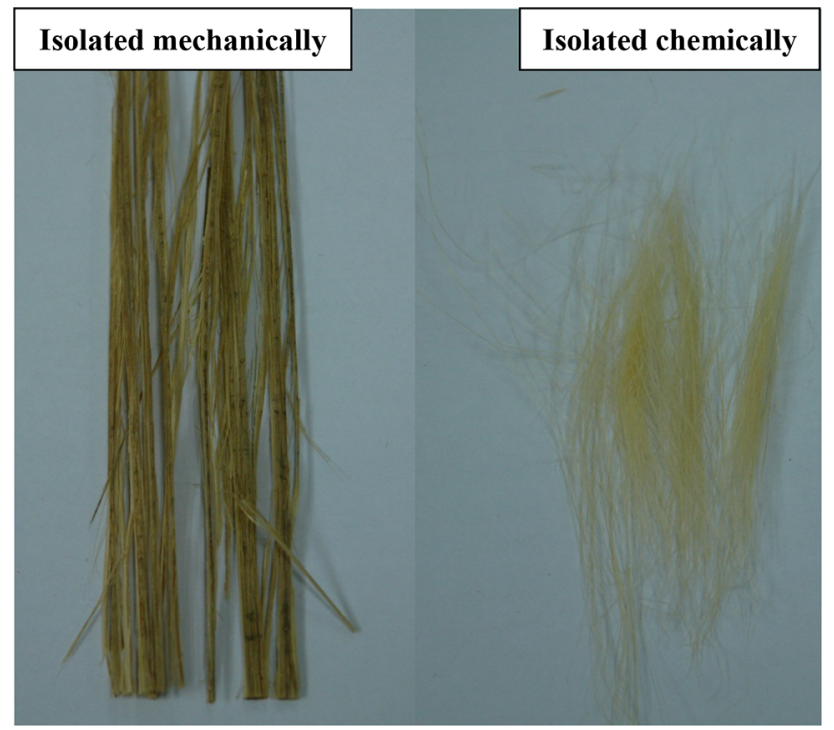

Fig. 3 Bamboo fiber bundles isolated mechanically and chemically, respectively

using tweezers from the strips after being fibrillated 6 times in a special device designed at International Centre for Bamboo and Rattan $[17,18]$. In our previous studies [17, 18], it was found that the tensile strength of bamboo strips fibrillated 4-8 times was between 0.09 and $0.10 \mathrm{GPa}$. Although the tensile strength of bamboo strips fibrillated was $47.6 \%$ lower than that without, the fibrillation treatment (4-8 times) helps the bamboo strips well distributed and suited to be used as primary units in the process of bamboo-based composites [17, 18]. The strips fibrillated 6 times were chosen for this study.

The bamboo strips were selected from the location between 4-6 m measured from the bottom of the bamboo trunk. Tensile samples for bamboo strip from inner and outer layers of bamboo with moisture between 8-12\% were cut into a dog bone shape using a laser cutting machine (CMA-6040, Guangdong, China) in accordance with the requirements described in GB/T 15780-1995 [19] as shown in Fig. 4.

\section{Tensile property testing}

Tensile strength testing of the single bamboo fibers was conducted in accordance with the procedure described in previous study $[15,20]$. The fibers were first glued on an organic, channeled glass plate with one droplet of glue at each end, and then placed in an oven at $60{ }^{\circ} \mathrm{C}$ for $24 \mathrm{~h}$ followed by $22{ }^{\circ} \mathrm{C}$ for at least $24 \mathrm{~h}$. The tensile testing of the single fibers was conducted with a custom-designed 
Fig. 4 The schematic of separation of bamboo inner and outer layers (a) and $\mathbf{b}$ the size of sample according to the description in GB/T 15780-1995 [19]; the unit is mm $\mathbf{a}$

\section{Inner layer}

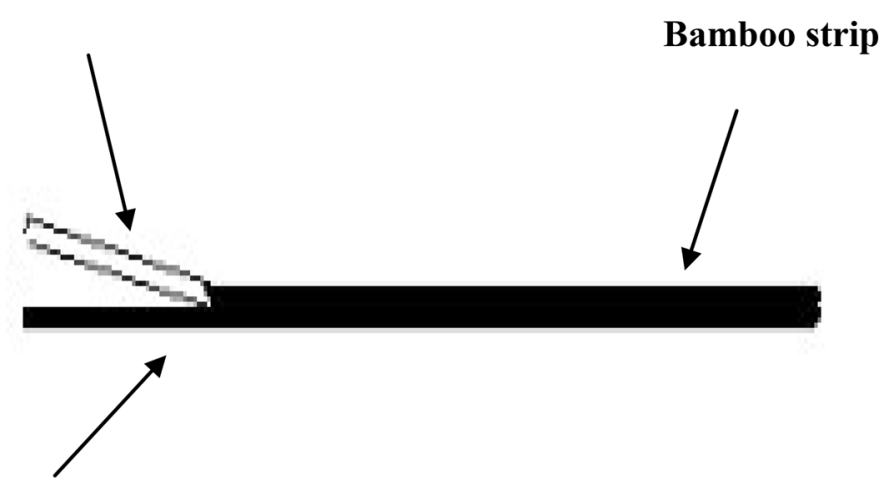

Outer layer

b

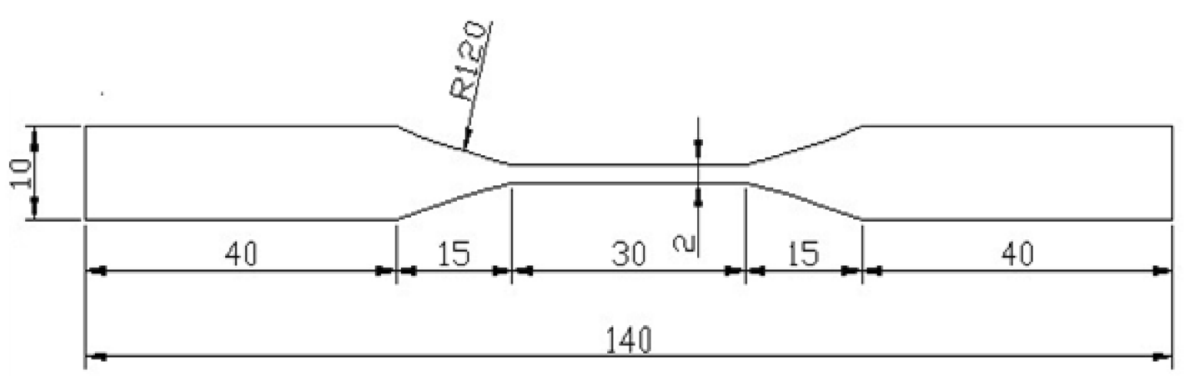

instrument (SF-Microtester I) with the measurement accuracy of $0.005 \mathrm{~N}$. The free test span of the single bamboo fiber was $1 \mathrm{~mm}$ (Fig. 5a). A constant strain rate of $48 \mu \mathrm{m} / \mathrm{min}$ was set at $25{ }^{\circ} \mathrm{C}$ and $20 \% \mathrm{RH}$. The fibers were removed from the tensile apparatus immediately upon failure and saved for subsequent cross-sectional area measurement with a confocal laser scanning microscope (CLSM; Zeiss, LSM 510 Meta, Germany) for tensile modulus and strength calculations. A typical cross-sectional area measurement using the CLSM is shown in Fig. 6a. Ten effective replicates were used for each sample type. For the testing of bamboo fiber bundles, the samples were glued onto an organic, channeled glass plate as a fiber bundle carrier to be easily fixed with one droplet of glue at each end (Fig. 5b). The free test span of the fiber bundles was $10 \mathrm{~mm}$. Before the testing, the samples were kept at room temperature for at least $3 \mathrm{~h}$ so that the glue droplet was fully cured. The tensile testing of single fibers was conducted at a high-resolution commercial mechanical tester with the measurement accuracy of $0.005 \mathrm{~N}$ (Microtester 5848, Instron, USA). A constant strain rate of $48 \mu \mathrm{m} / \mathrm{min}$ was used during the testing. The ambient room environment was $25{ }^{\circ} \mathrm{C}$ in temperature and $20 \%$ in $\mathrm{RH}$. The tested fibers were stained with a dilute concentration of acridine orange, attached to a glass slide and covered with a cover slip. The images of cell wall cross section were
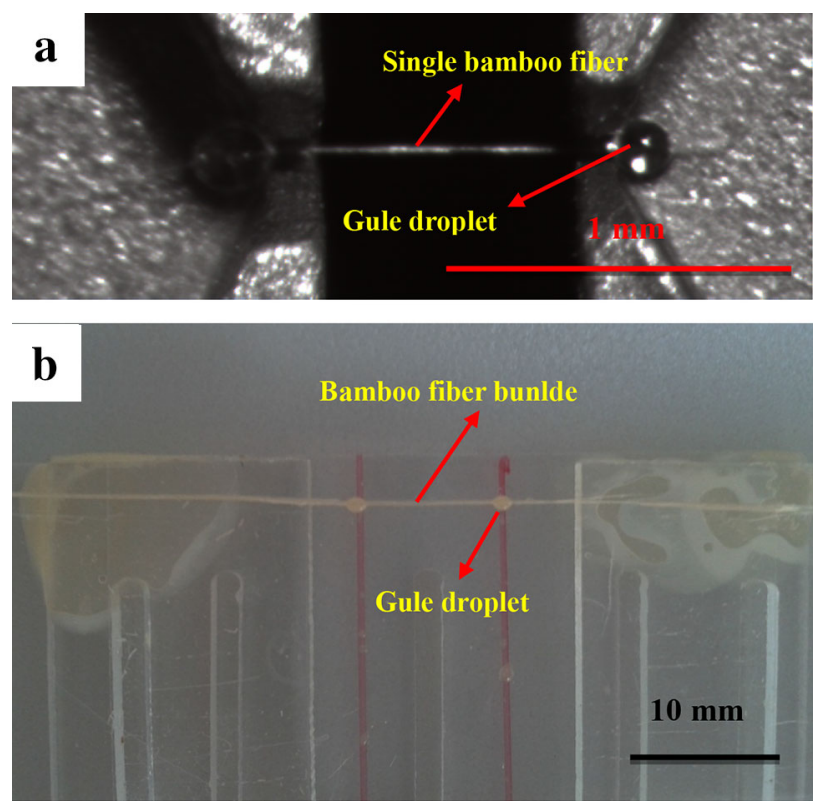

Fig. 5 The samples for tensile property testing of single bamboo fiber (a) and bamboo fiber bundle (b)

obtained by CLSM, from which the areas were calculated by the software in the CLSM (Fig. 6b). Six effective replicates were tested. 

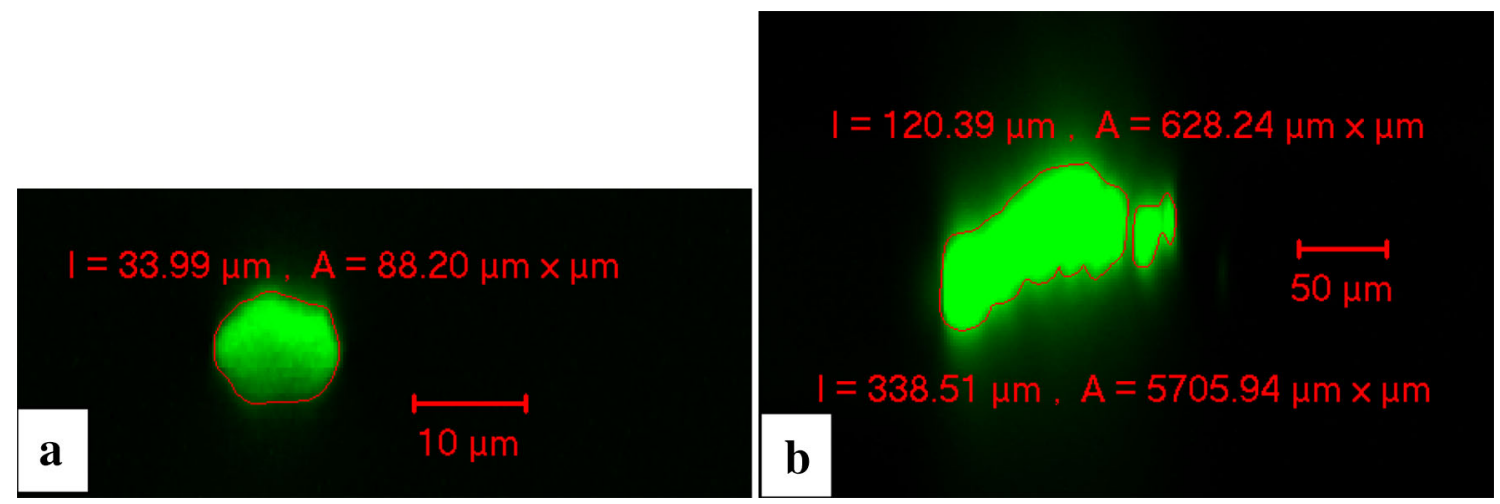

Fig. 6 Typical confocal laser scanning microscope (CLSM) images of area of cross section ( $I$ circumference, $A$ area). a Cross section of single bamboo fiber; $\mathbf{b}$ cross section of bamboo fiber bundle

Fig. 7 The tensile property testing of bamboo strips, a the sample of bamboo, $\mathbf{b}$ the sample of bamboo with wood slices for protection, $\mathbf{c}$ tensile testing process

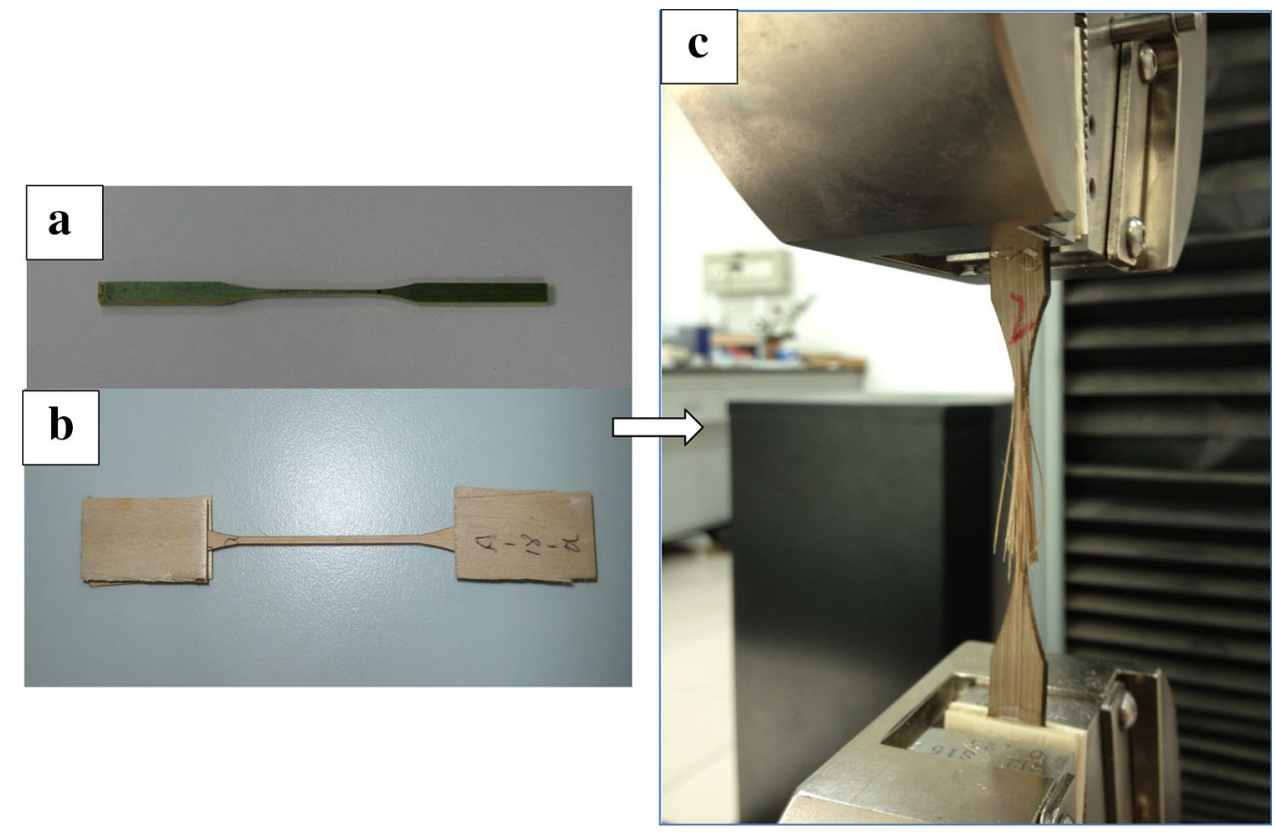

The testing of bamboo strip was performed by a highresolution commercial mechanical tester (Microtester 5582, Instron, USA) with a strain rate at $1.0 \mathrm{~mm} / \mathrm{min}$ at an ambient environment of $25^{\circ} \mathrm{C}$ and $12 \% \mathrm{RH}$ (shown in Fig. 7). Contact extensimeter was used for obtaining tensile strain which was used for calculating tensile modulus. Six effective samples were tested for each type. All the stain in this study was determined by cross-head displacement.

\section{Results and discussion}

\section{Tensile properties of single bamboo fibers}

The tensile properties of single bamboo fibers isolated chemically and mechanically are shown in Table 1 , from which it was seen that the tensile properties of the single bamboo fibers were affected by the isolation methods. The tensile strength of chemically isolated fibers was higher than that of mechanically isolated fibers, whereas the modulus and elongation were lower.

An analysis of the chemical component of the fibers was conducted using the FT-Raman spectra. In Fig. 8, the most intense band in the fingerprint region $\left(800-1800 \mathrm{~cm}^{-1}\right.$ ) was shown at $1600 \mathrm{~cm}^{-1}$ for mechanically isolated fibers, which attribute to the aryl ring (in lignin) stretching and aryl ring symmetric vibration (Table 2) [21]. Differences between the chemical retting were observed in the fingerprint regions, with the absence of the peak at $1600 \mathrm{~cm}^{-1}$ for chemically isolated fibers. Therefore, we can conclude that lignin degradation happened in the chemically isolated fibers. 
Table 1 Tensile properties of single bamboo fibers isolated by different methods

\begin{tabular}{llll}
\hline Single bamboo fibers & TS, GPa $(\mathrm{CV})$ & TM, GPa $(\mathrm{CV})$ & $E, \%(\mathrm{CV})$ \\
\hline Chemically isolated & $1.77(0.15)$ & $26.85(0.06)$ & $2.89(0.16)$ \\
Mechanically isolated & $0.93(0.19)$ & $34.62(0.17)$ & $4.30(0.17)$ \\
\hline
\end{tabular}

$T S$ tensile strength, $T M$ tensile modulus, $E$ elongation

Fig. 8 FT-Raman spectra of single bamboo fibers isolated chemically and mechanically in the fingerprint area. $B F C$ bamboo fiber isolated chemically, $B F M$ bamboo fiber isolated mechanically

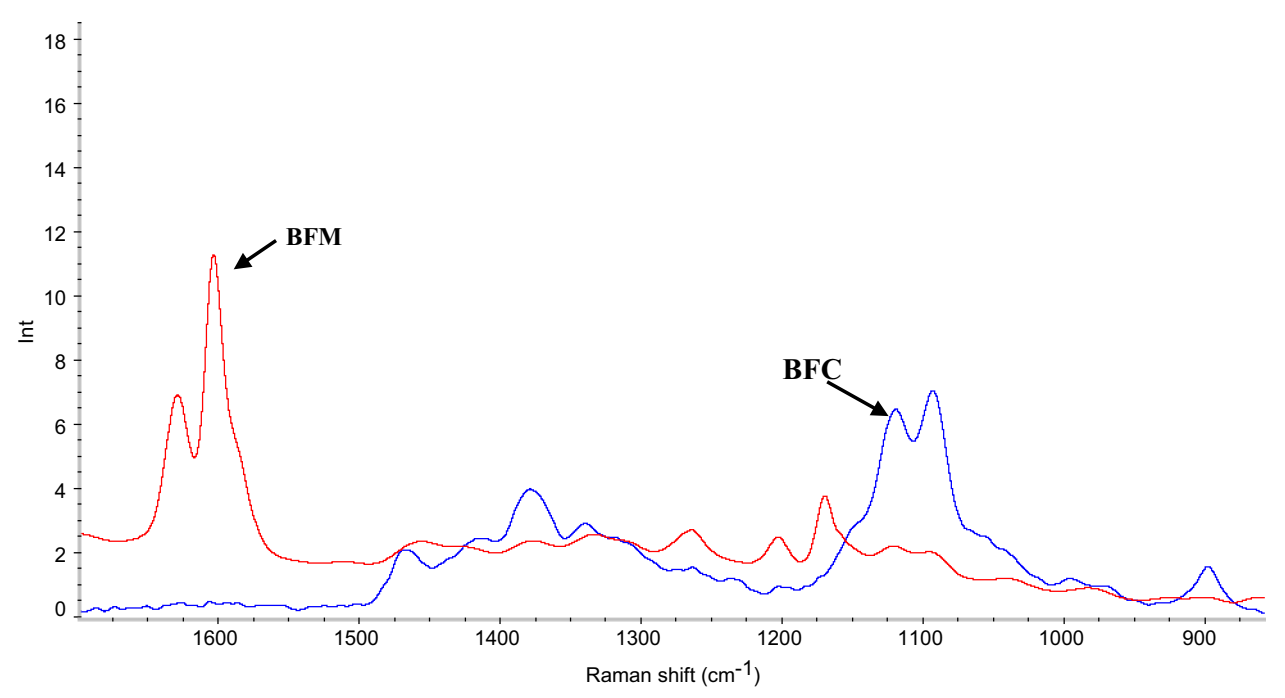

Table 2 Assignment of bands in the FT-Raman spectrum of cell wall polymers [21]

\begin{tabular}{lll}
\hline & $\begin{array}{l}\text { Wavenumber } \\
\left(\mathrm{cm}^{-1}\right)\end{array}$ & Band assignment \\
\hline Lignin & 1600 & Aryl ring stretching, symmetric \\
& 895 & HCC and HCO bending at C6 \\
Cellulose & 1377 & HCC, HCO and HOC bending \\
& 1456 & HCH and HOC bending \\
Carbohydrates & 1095 & CC and CO stretching \\
\hline
\end{tabular}

The cell wall structure model was established by Boyd allowed for an essentially lamellar distribution of cellulose [22], but a non-lamellar distribution of lignin. Adjacent cellulose fibrils linked to each other and formed the discshaped openings filled up with matrix made up of hemicellulose and lignin. With the degradation of cellulose in the cell wall, cellulose fibrils aggregated and connected each other in longitudinal direction, which increased the fracture resistant. Meanwhile, Chen et al. found that the cross-sectional area of mechanically retted fibers was smaller compared with those retted chemically [15]. As shown in Fig. 9a, no fracture is observed on the surface of fiber isolated chemically, while predominant plane fractures were produced when the fiber was peeled with fine tweezers (Fig. 9b). This is another reason for the lower tensile strength of mechanically isolated fibers. Zhang found that the tensile strength of single Chinese fir fibers increased when the lignin content was reduced, while the modulus and elongation decreased [23]. It was also investigated by Zhang that lignin was attributed to modulus, which explain, to a certain extent, why the modulus of single bamboo fibers isolated mechanically is higher than that isolated chemically.

\section{Tensile properties of bamboo fiber bundles}

It is seen from Table 3 that tensile strength, modulus and elongation of chemically isolated bamboo fiber bundles were all higher than that of mechanically isolated bamboo fiber bundles. For the chemical retting process, the alkali treatment leaded to a large removal of lignin and hemicellulose $[24,25]$. Tensile properties of fiber bundles isolated chemically are higher due to the destruction of hemicellulose and lignin that surrounded by and cemented with the cellulose. In addition, the alkali treatment removed part of the lignin-rich middle lamella, which reduced the damage caused by the combing process in the preparation of bamboo bundles. These lead to an increase in the mechanic al properties of fiber bundles isolated chemically. In contrast, bamboo fiber bundles retted mechanically (fiber bundles were peeled with tweezers from fibrillated bamboo strips) were damaged more in the middle lamella. Besides, more failures happened near the glue droplet of mechanically isolated bamboo fiber bundles compared with that of isolated chemically. That also revealed that the 

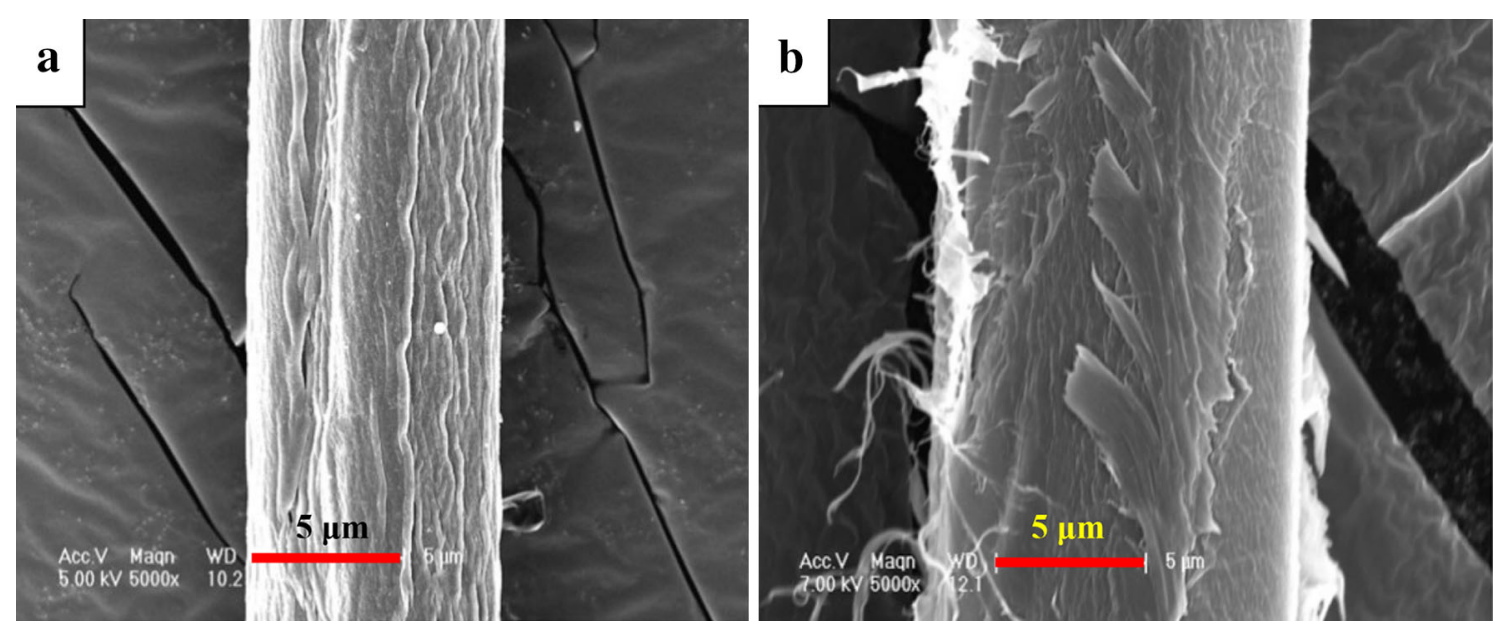

Fig. 9 Environment scanning electron microscope (ESEM) images of single bamboo fibers isolated differently [15]. a Fibers isolated chemically; b fibers isolated mechanically

Table 3 Tensile properties of bamboo bundles made by different methods

\begin{tabular}{llll}
\hline Bamboo fiber bundles & TS, GPa (CV) & TM, GPa (CV) & $E, \%(\mathrm{CV})$ \\
\hline Chemically isolated & $0.61(0.37)$ & $23.56(0.35)$ & $2.61(0.32)$ \\
$\begin{array}{l}\text { Mechanically } \\
\text { isolated }\end{array}$ & $0.29(0.71)$ & $16.50(0.42)$ & $1.68(0.31)$ \\
\hline
\end{tabular}

mechanical retting caused more damage because of the stress concentration. The higher strain of fiber bundles isolated chemically than that isolated mechanically indicates the introduction of ductility into the fibers after the alkali treatment, which is in co-ordinance with the results found by Chen and Hossain et al. [26, 27].

\section{Tensile properties of bamboo strip}

As shown in Table 4, the tensile strength and modulus along the grain direction of samples made from outer portion of bamboo were higher compared to those made from the inner portion of bamboo. However, the tensile strength and modulus of bamboo strips were lower than that of samples made from outer portion of the bamboo but higher than that of samples made from inner portion of the bamboo.

The density of vascular bundles, the amount of fibers and the thickness of fibers maybe the factors affecting the tensile properties of bamboo fiber [28]. The differences in the structure are mainly responsible for the phenomenon that the tensile strength of the outer layer is greater than the inner one. Bamboo can be considered as a natural composite. The cells in bamboo are classified into two types: (1) the cell in basic tissues for transmitting load which has high tensile strength, but low modulus and low density; (2)
Table 4 Tensile properties of bamboo strips

\begin{tabular}{llll}
\hline Samples & TS, MPa (CV) & TM, GPa (CV) & $E, \%(\mathrm{CV})$ \\
\hline BS & $0.30(0.02)$ & $19.85(0.05)$ & - \\
BOL & $0.33(0.04)$ & $25.51(0.06)$ & - \\
BIL & $0.26(0.01)$ & $18.53(0.05)$ & - \\
\hline
\end{tabular}

$\overline{B S}$ bamboo strips, $B I L$ bamboo inner layer, $B O L$ bamboo outer layer

vascular, structurally consisting of fibers and lignified vessels. The fibers in vascular, with high tensile strength, modulus and density, are the main components responsible for the mechanical properties of bamboo [29]. The vascular bundles are surrounded by the basic tissues. The tissue amount of tissue decreased from inner to outer portions of the bamboo. Therefore, the fibers in outer portion of bamboo are more comparable to those from the inner portion of bamboo as shown in Fig. 1b [30]. The amount of vascular bundles determines the mechanical properties of bamboo. The higher the vascular bundle content, the greater the tensile strength and modulus for the bamboo [31]. It was also shown in Fig. 1b that the amount of fibers in one vascular bundle from the outer layer was much more than that from the inner layer, which explained that higher tensile strength and modulus presented for the bamboo strips obtained from the outer layer.

In the tensile testing of bamboo strips, shear failures happened first at one end of most samples, followed by the tensile failure. Most of the specimens that in shear failures were those made from the outer portion of the bamboo (Fig. 10a). Most of the specimens that failed in tension were those made of the inner portion of bamboo (Fig. 10b). The strength of the specimen that was in shear failure was generally higher than that failed in tension. 

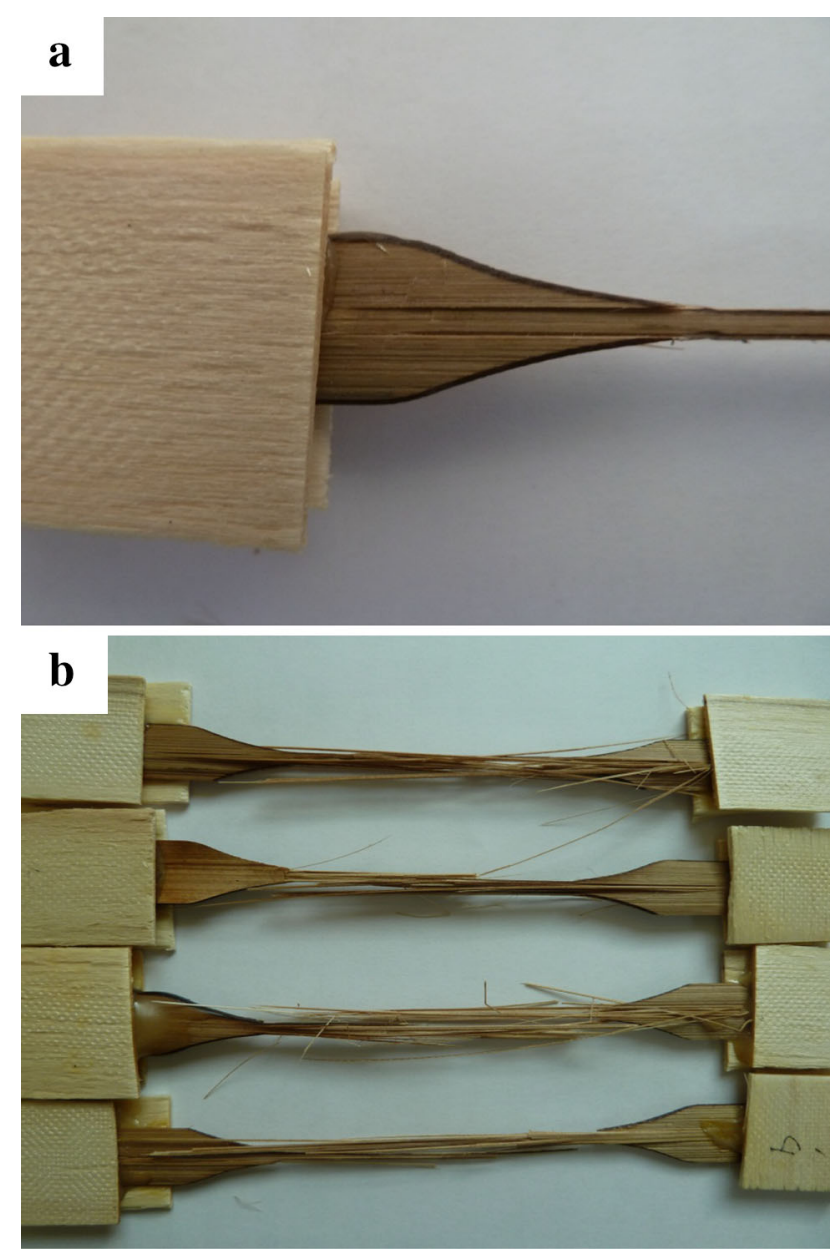

Fig. 10 Typical image of bamboo fracture, a the specimen in shear failures, $\mathbf{b}$ the specimen failed in tension

\section{Relationship of tensile properties between bamboo units in different sizes}

The average tensile strength, modulus and elongation of chemically retted single bamboo fibers were obtained as $1.77 \mathrm{GPa}, 23.56 \mathrm{GPa}$ and $2.89 \%$, respectively. In the comparison of bamboo fiber bundle and bamboo single fiber, the tensile strength was decreased by $65.5 \%$, the modulus by $12.3 \%$, and the elongation by $9.7 \%$. For the mechanically retted single bamboo fibers, an averaged tensile strength of $0.93 \mathrm{GPa}$, modulus of $34.6 \mathrm{GPa}$ and elongation of $4.3 \%$ were obtained as shown in Fig. 11. For both mechanically retted bamboo fiber bundles and single bamboo fibers, the tensile strength, modulus and elongation of bamboo fiber bundles were obtained as $68.8,52.3$ and $60.9 \%$, respectively, which were lower than that of single bamboo fibers. Most failures for the tested specimens happened in the parenchyma between the single fibers. Figure 12 shows the failure modes of the specimens for the bamboo fiber bundles. Most failures were that fibers being pulled out. Shao et al. studied the behaviors of Mode I
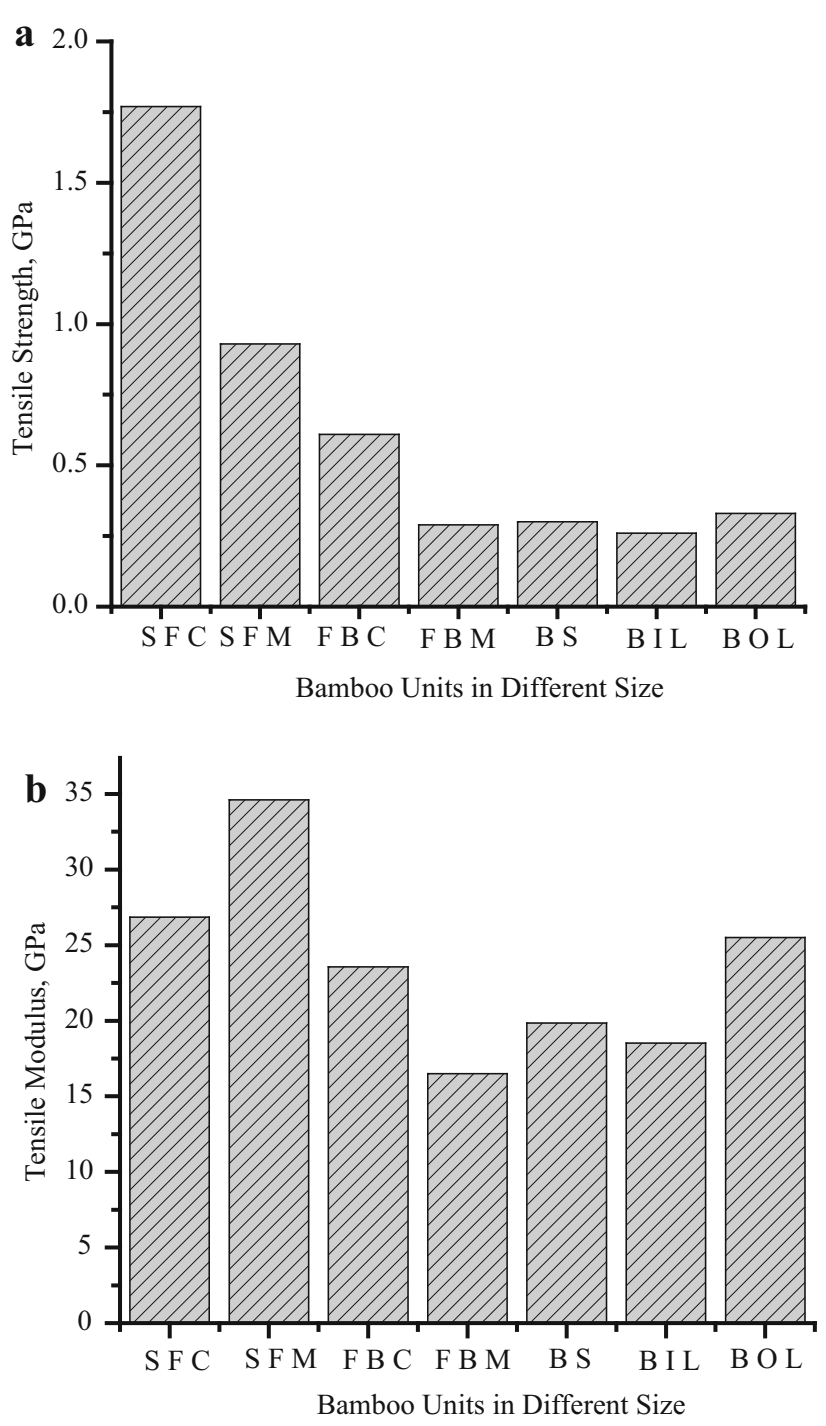

Fig. 11 Regularity of tensile strength (a) and tensile modulus (b) of bamboo units in different sizes. $S F C$ single bamboo fibers isolated chemically, $S F M$ single bamboo fibers isolated mechanically, $F B C$ bamboo fiber bundles isolated chemically, $F B M$ bamboo fiber bundles isolated mechanically, $B S$ bamboo strips, $B I L$ bamboo inner layer, $B O L$ bamboo outer layer)

(crack opening mode) interlaminar fracture parallel to grain of moso bamboo, and observed that the crack propagation developed along the longitudinal interface between the fibers and ground tissue, indicating that the longitudinal interfacial strength was weak among bamboo cells [32].

As shown in Fig. 13, some bamboo fiber bundles contain parenchyma with lower tensile strength in comparison with the single bamboo fibers [32]. As the existence of weak interface among the parenchyma, the crack propagation easily happened resulting in an ultimate failure [33]. The isolation method also affected the property reduction rate from single fibers to fiber bundles. The chemical treatment had less property reduction compared to the mechanical one. 

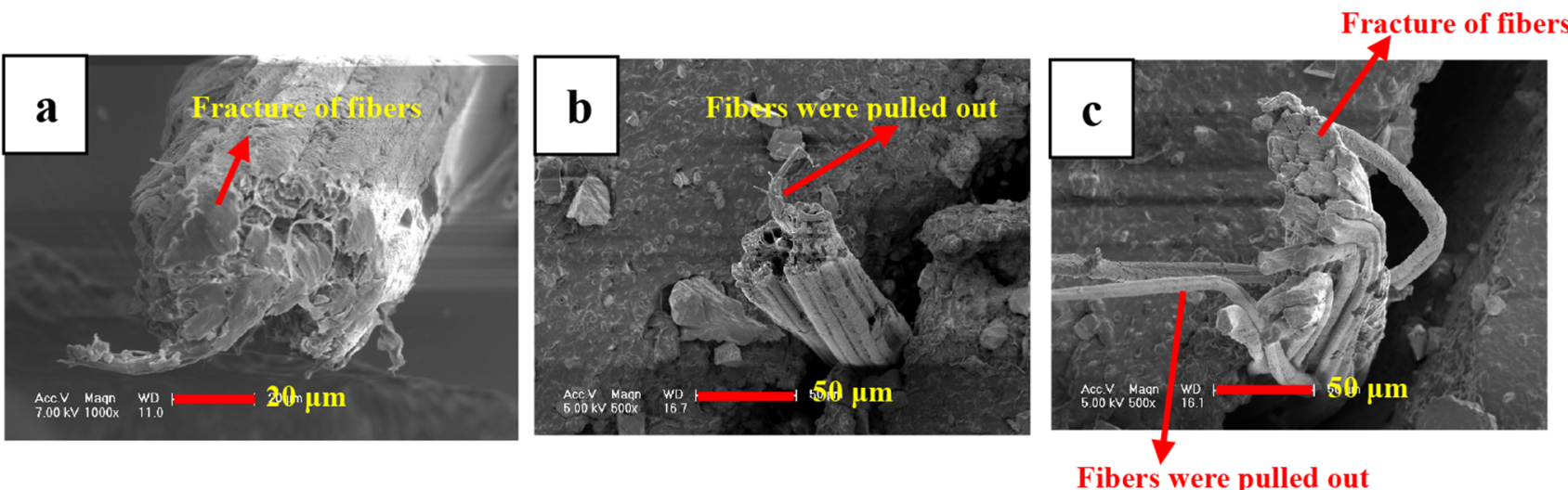

Fig. 12 Typical ESEM images of fracture modes of bamboo fiber bundle, the fracture of all single fibers (a); fibers were pulled out (b); both fracture of single fibers and fibers being pulled out (c)

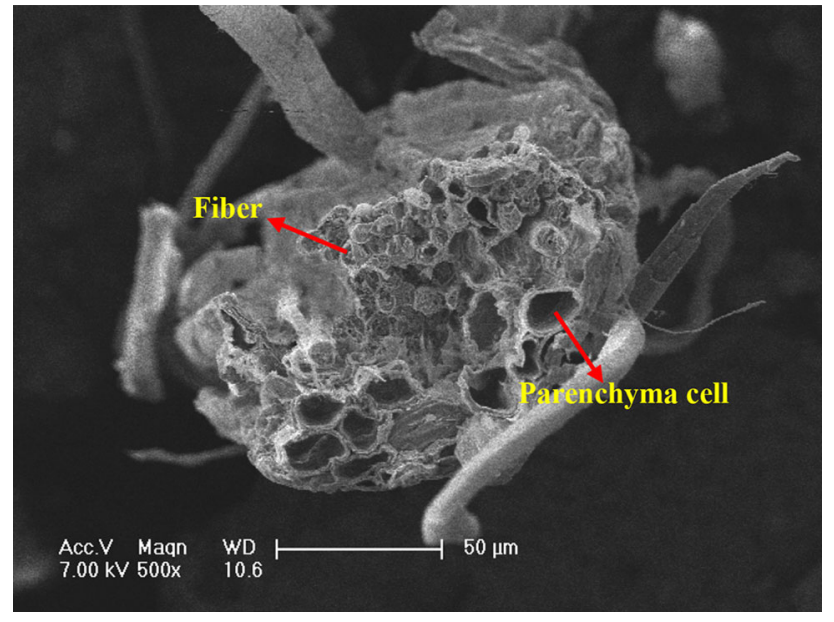

Fig. 13 Typical ESEM images of parenchyma cell in the bamboo fiber bundles

As shown in Fig. 11, the tensile strength of bamboo strips was $67.7 \%$ of that of the single fibers when retted mechanically, whereas the modulus was $42.7 \%$. Bamboo is made up of vascular bundles with parenchyma in between, where the interface between vascular bundles and parenchyma is weak [34]. During the tensile testing, the crack propagation in the specimen first happened in the parenchyma area. As the stress continues to increase, slips happened at the interface between bamboo fiber bundles and parenchyma, then cracks appeared at the other weak interface, such as interface between bamboo fibers, interface between parenchymas, and in the end, the bamboo fiber bundles were pulled out slowly from parenchyma [33]. Compared with single bamboo fibers, weak interface area presented in bamboo and bamboo fiber bundles that lead to a huge reduction in the mechanical properties.

For the bamboo fibers obtained from mechanical retting process, the tensile strength of bamboo strip was $3.3 \%$ higher than that of fiber bundle isolated mechanically, while tensile modulus was $16.9 \%$ higher than fiber bundles. In the preparation of bamboo fiber bundles, some parenchyma was removed or damaged during the fibrillation process, and the single fibers in the fiber bundle were also damaged. Therefore, the tensile strength of bamboo strip was higher than that of bamboo fiber bundle. The tensile modulus of the parenchyma in the fiber is much lower than that in bamboo fiber bundles as more parenchyma is present in the bamboo strips. This may partially explain that the tensile modulus of bamboo strips is lower than that of the bamboo fiber bundle.

\section{Conclusion}

The mechanical properties of bamboo single fiber, fiber bundles and strips were characterized. The fibers obtained from two retting methods were compared. For the single bamboo fibers, the tensile strength of chemically isolated samples is higher than that of mechanically isolated ones, whereas the modulus and elongation are lower. For the bamboo fiber bundles, the tensile strength, modulus and elongation of chemically treated samples are higher compared to the mechanically isolated ones.

For the bamboo strips, the tensile strength and modulus were lower than that of samples made from the outer portion of the bamboo but higher than inner portion of the bamboo. For the chemical isolated fiber, the tensile strength of the bamboo fiber bundle was decreased by $65.7 \%$ compared to that of the single fiber, modulus by $12.3 \%$, and elongation by $9.7 \%$. For both single bamboo fibers and bamboo bundles retted mechanically, the tensile strength, modulus and elongation of bamboo fiber bundles were obtained as $68.8,52.3$ and $60.9 \%$ lower than that of the single bamboo fibers, respectively. In addition, the 
mechanical properties of bamboo fiber bundles retted chemically showed much lower than the single fiber compared to the one retted mechanically.

Compared to the single bamboo fibers and bamboo fiber bundles, the tensile strengths of bamboo strips were reduced by 67.7 and $3.3 \%$, respectively. The modulus of bamboo fiber bundles decreased by $42.7 \%$ compared to the single bamboo fibers, whereas increased by $16.9 \%$ compared to the bamboo fiber bundles.

Acknowledgments This work is funded by the China Nature Science Foundation (CNSF) (31170525), Technical Supporting 12th Five-year Plan Project (2012BAD23B0203) and the Priority Academic Program Development of Jiangsu Higher Education Institutions (PAPD). Dr. Lin kindly assisted with preparing the manuscript. Wang Hankun, Shang Lili and Zhang Dan provided substantial help during the experiments. The constructive comments from the anonymous reviewers are greatly appreciated.

\section{References}

1. Jayne BA (1959) Mechanical properties of wood fibers. Tappi 42(6):461-467

2. Kersavage PC (1973) A system for automatically recording the load-elongation characteristics of single bamboo fibers under controlled relative humidity conditions. USDA. U.S. Government Printing Office

3. Mott L, Groom L, Shaler S (2002) Mechanical properties of individual southern pine fibers. Part II. Comparison of earlywood and latewood fibers with respect to tree height and juvenility. Wood Fiber Sci 34(2):221-237

4. Groom L, Shaler S, Mott L (2002) Mechanical properties of individual southern pine fibers. Part III. Global relationship between fiber properties and fiber location within and individual tree. Wood Fiber Sci 34(2):238-250

5. Burgert I, Eder M, Fruhmann K, Keckes J, Fratzl P (2005) Properties of chemically and mechanically isolated fibres of spruce (Picea abies [L.] Kart.). Part 3: mechanical characterisation. Holzforschung 59:354-357

6. Wang G, Shi S, Wang JW, Yu Y, Cao SP, Cheng HT (2011) Tensile properties of four types of individual cellulosic fibers. Wood Fiber Sci 43(4):353-364

7. Yu Y, Jiang ZH, Fei BH, Wang G, Wang HK (2011) An improved microtensile technique for mechanical characterization of short plant fibers: a case study on bamboo fibers. J Mater Sci 46:739-746

8. Okubo K, Fujii T, Thostenson ET (2009) Multi-scale hybrid biocomposite: processing and mechanical characterization of bamboo fiber reinforced PLA with microfibrillated cellulose. Compos A 40(4):469-475

9. Zhai SC, Li DG, Pan B, Sugiyama J, Itoh T (2012) Tensile strength of windmill palm (Trachycarpus fortunei) fiber bundles and its structural implications. J Mater Sci 47:949-959

10. Shito T, Okubo K, Fujii T (2002) Development of eco-composites using natural bamboo fibers and their mechanical properties. HI Per Struct Mat 4:175-182

11. Tung NH, Yamamoto H, Matsuoka T, Fujii T (2004) Effect of surface treatment on interfacial strength between bamboo fiber and PP resin. JSME Int J Ser A 47(4):561-565

12. Tokoro R, Vu DM, Okubo K, Fujii T (2008) How to improve mechanical properties of polylactic acid with bamboo fibers. J Mater Sci 43:775-787
13. Wang G (2003) Moso bamboo/Chinese fir laminated composite and its properties. $\mathrm{PhD}$ dissertation. Chinese Academy of Forestry, Beijing, pp 48-53

14. Li XZ (2009) Research on mechanical and failure properties of moso bamboo. PhD dissertation. Chinese Academy of Forestry, Beijing, pp 45-53

15. Chen H, Wang G, Cheng HT (2011) Properties of single bamboo fibers isolated by different chemical methods. Wood Fiber Sci 43(2):111-120

16. Hossain MK, Dewan MW, Hosur M, Jeelani S (2011) Mechanical performances of surface modified jute fiber reinforced biopol nanophased green composites. Compos B 42:1701-1707

17. Zhang WF, Wang G, Yu ZX, Cheng HT, Qiu YX (2012) Effects of bamboo shape on properties of bamboo/wood LVL (in Chinese). J Nanjing For Univ 36:167-169

18. Yu ZX (2012) Processing technology of laminated bamboobundle veneer lumber and its application performance. $\mathrm{PhD}$ dissertation. Chinese Academy of Forestry, Beijing

19. GB/T 15780-1995(1996) Testing methods for physical and mechanical properties of bamboo. GB Standards, China

20. Cao SP, Wang G, Yu Y, Cheng HT, Chen H (2010) Comparison of mechanical properties of different single vegetable fibers (in Chinese). J Nanjing For Univ 34:87-90

21. Agarwal UP, Ralph SA (1997) FT-Raman Spectroscopy of wood: identifying contributions of lignin and carbohydrate polymers in the spectrum of black spruce (Picea mariana). Appl Spectrosc 51(11):1648-1655

22. Boyd JD (1982) An anatomical explanation for visco-elastic and mechanosorptive creep in wood, and effects of loading rate on strength. In: Baas P (ed) New perspective in wood anatomy. Martinus Nijhoff/Dr W Junk Publishing, La Hague, pp 172-222

23. Zhang SY (2011) Chemical components effect on mechanical properties of wood cell wall. PhD dissertation. Chinese Academy of Forestry, Beijing, pp 48-55

24. Xu W, Tang RC (2006) Extracting natural bamboo fibers from crude bamboo fibers by caustic treatment. Biomass Chem Eng 40(3): $1-5$

25. Guimarães J, Frollini E, Da SC, Wypych F, Satyanarayana K (2009) Characterization of banana, sugarcane bagasse and sponge gourd fibers of Brazil. Ind Crops Prod 30:407-415

26. Chen H (2014) Study on the structural characteristics of bamboo cell wall. PhD dissertation. Chinese Academy of Forestry, Beijing, pp 83-99

27. Hossain MK, Karim MR, Chowdhury MR, Imam MA, Hosur M, Jeelani S, Farag R (2014) Comparative mechanical and thermal study of chemically treated and untreated single sugarcane fiber bundle. Ind Crops Prod 58:78-90

28. Xian XJ, Xian DG (1990) The relationship of microstructure and mechanical properties of bamboo. J Bamboo Res 9(3):10-23

29. Liu B (2008) Formation of cell wall in development culms of Phyllostachys pubescens. PhD dissertation. Chinese Academy of Forestry, Beijing, pp 159-161

30. Jiang ZH (2002) Anatomical structure of bamboo culms and leaves, bamboo and rattan in the world. Liaoning Science and Technology Press, Liaoning

31. Amada S, Ichikawa Y, Munekata T, Nagase Y, Shimizu H (1997) Fiber texture and mechanical graded structure of bamboo. Compos B 28:13-20

32. Shao ZP, Fang CH, Tian GL (2009) Mode I interlaminar fracture property of moso bamboo (Phyllostachys pubescens). Wood Sci Technol 43(5-6):527-536

33. Tian GL, Jiang ZH, Yu Y, Wang HK, An X (2012) Toughness mechanism of bamboo by in situ tension. J Beijing For Univ 34(5):144-147

34. Shao ZP (2007) Wood damage-fracture and wood meso-damage elements. Sci Silvae Sin 43(4):107-110 